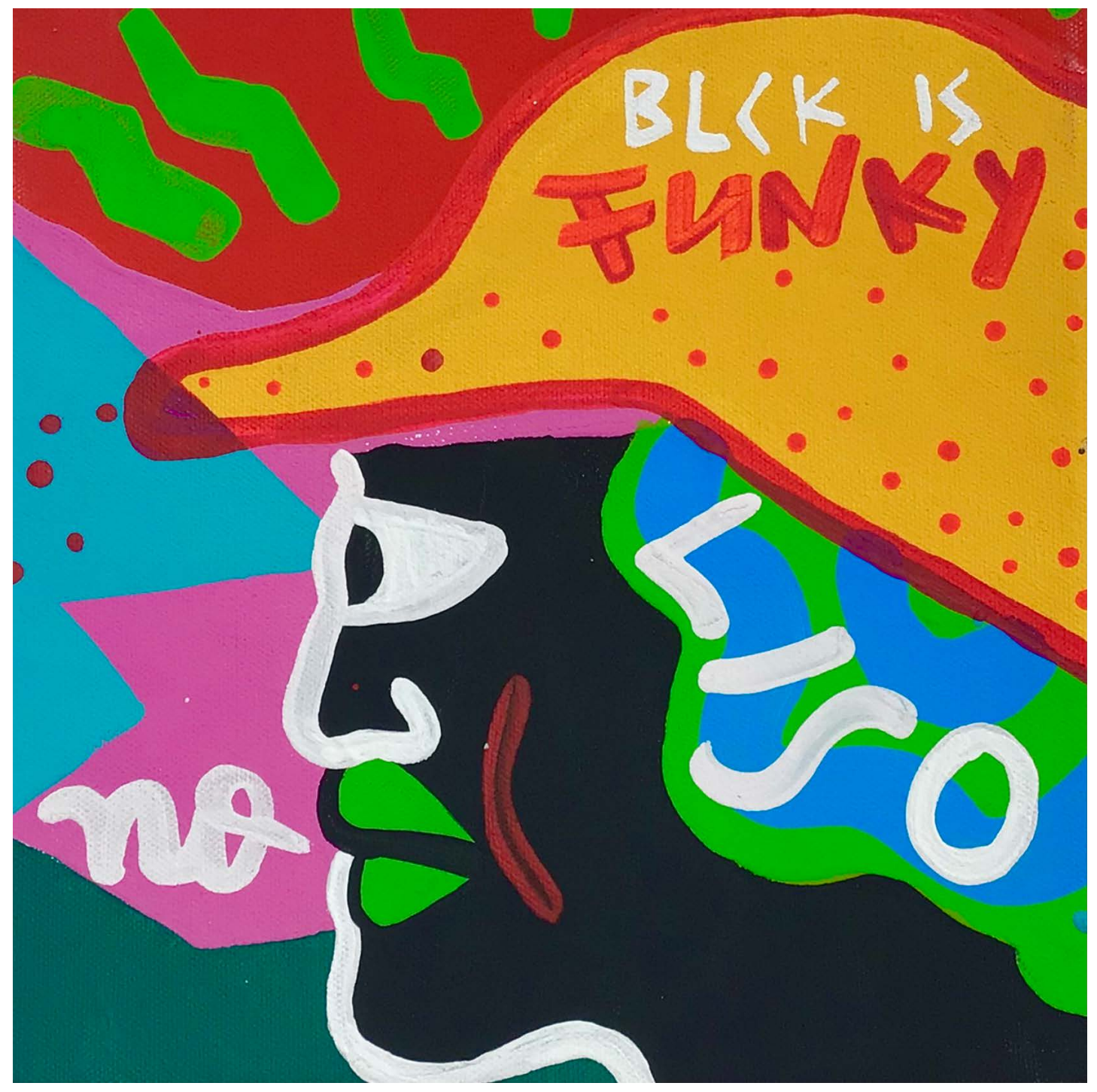

Artista invitado

Fabio Andrés Arboleda Mendoza

Liso

De la serie neWeed

Acrílico sobre lienzo

$20 \times 20 \mathrm{~cm}$

2020

Medellín 


\title{
Pensar la formación de la subjetividad política a partir de la voluntad de ficción de Friedrich Nietzsche*
}

\author{
Edisson Leonardo Parra Herrera (Colombia) ${ }^{* *}$
}

\section{Resumen}

Este artículo responde a la demanda de pensar una noción de política y de subjetividad más allá de los marcos de la racionalidad moderna hegemónica. Para ello se exploran qué elementos propios de la subjetividad política pueden pensarse a partir del entramado conceptual que gira alrededor de la noción de voluntad de ficción de Friedrich Nietzsche. Se parte del supuesto de que es posible encontrar un pensamiento o filosofía política en el autor alemán que puede denominarse agonismo interpretativo o hermenéutico. Se resalta que es posible, a partir del concepto focalizado, pensar en la formación de la subjetividad política, teniendo en cuenta los siguientes elementos: la consciencia de poder del carácter ficcional y relacional de la existencia; la posibilidad de transformación de las estructuras de poder desde la configuración de sentidos a partir de la óptica del cuerpo, la tierra y la vida; y la transfiguración de la propia subjetividad.

\section{Palabras clave}

Filosofía Política; Hermenéutica Fisiológica; Voluntad de Ficción; Subjetividad Política; Agonismo; Nietzsche, Friedrich.

Fecha de recepción: noviembre de 2020

- $\quad$ Fecha de aprobación: abril de 2021

\footnotetext{
*Artículo resultado del proyecto de investigación y tesis de doctorado en Educación de la Universidad de los Andes Voluntad de ficción, subjetividades políticas y narraciones (auto) biográficas. Una experiencia de formación política con estudiantes de secundaria), y financiado parcialmente por la Secretaría de Educación Distrital de Bogotá y el Departamento Administrativo de Ciencia, Tecnología e Innovación (Colciencias), Becas doctorados nacionales, convocatoria 757 de 2016. También se contó con crédito condonable de la Universidad de los Andes.

${ }^{* *}$ Licenciado En Educación Básica con Énfasis en Ciencias Sociales. Magíster en Filosofía. Doctor en Educación. Docente coordinador Secretaría de Educación Distrital de Bogotá. Correo electrónico: el.parra10@uniandes.edu.co - Orcid: 0000-0001-8708-1875 - Google Scholar: https://scholar.google. com/citations?user $=$ HLlhXqAAAAAJ\&hl=es
} 


\title{
Cómo citar este artículo
}

Parra Herrera, Edisson Leonardo. (2021). Pensar la formación de la subjetividad política a partir de la voluntad de ficción de Friedrich Nietzsche. Estudios Políticos (Universidad de Antioquia), 62, pp. 127-150. https://doi.org/10.17533/udea.espo. n62a06

\section{Thinking the Formation of Political Subjectivity Based on the Will to Fiction of Friedrich Nietzsche}

\begin{abstract}
This article responds to the demand for thinking about a notion of politics and subjectivity beyond the modern and hegemonic rationality frames. To that end, it explores the elements of the political subjectivity that can be thought with the conceptual framework that revolves around the notion of the will to fiction of Friedrich Nietzsche. This way, we start from the assumption that it is possible to find a thought or political philosophy in the German author that can be called interpretive or hermeneutic agonism. As a result, we highlight the feasibility to think about the formation of subjectivity, based on the will to fiction, taking into account the following elements: the consciousness of the power of the fictional, and

[128] relational nature of existence; the possibility of transformation of power structures from the configuration of senses from the perspective of the body, the earth, and life; furthermore, the transfiguration of one's own subjectivity.
\end{abstract}

\section{Keywords}

Political Philosophy; Philosophical Hermeneutics; Will to Fiction; Political Subjectivity; Agonism; Nietzsche, Friedrich. 
A pesar de todo esto, yo soy también, necesariamente, el hombre de la fatalidad. Pues cuando la verdad entable lucha contra la mentira de milenios tendremos conmociones, un espasmo de terremotos, un desplazamiento de montañas y valles como nunca antes se había soñado. El concepto de política queda entonces totalmente absorbido en una guerra de los espíritus, todas las formaciones de poder de la vieja sociedad saltan por el aire - todas ellas se basan en la mentira: habrá guerras como jamás las ha habido en la tierra. Solo a partir de mí existe en la Tierra la gran política-

(Nietzsche, 2003, p. 136).

\section{Consideraciones introductorias sobre política, ficción y subjetividad en Friedrich Nietzsche}

"Yo no soy un hombre, soy dinamita», dice Nietzsche en Ecce homo (2003, p. 135), a partir de lo cual parece factible hacer una lectura política de su filosofía. Sobre todo, cuando lo dice antes de anunciar la destrucción de las formaciones de poder de la vieja sociedad. El nombre con el que designa al proceso por el cual se descubre que se ha denominado verdad a la mentira es el de «transvaloración de todos los valores». En este camino, el matiz político del pensamiento nietzscheano es subrayado por Jesús Conill (1997):

Y es que la transvaloración nietzscheana es una forma de hermenéutica, cuya transformación se rige por parámetros suministrados desde una fisiología que tiene relevancia política; de ahí que la transvaloración sea fisiológica y que tenga carácter político (constituya también una empresa política), porque tiene como resultado la transformación de las estructuras de poder y las formas de existencia (p. 174).

En este proyecto se observan los elementos sobre los que consuma su pensamiento en el periodo final: la hermenéutica, la fisiología, la genealogía y la política (Vermal y Llinares, 2008). Con base en estos caracteres y con el supuesto de que es posible evidenciar un pensamiento político en Nietzsche, este artículo tiene como propósito proponer elementos constitutivos de la subjetividad política a partir de la filosofía política del autor alemán. Estos serían principalmente: la consciencia de poder del carácter relacional, tanto como ficcional de la experiencia; la posibilidad 
de transformación de las estructuras de poder desde la configuración de sentidos a partir de la óptica del cuerpo, la tierra y la vida; además, la transfiguración de la propia subjetividad.

Para desarrollar esto el texto se divide en cinco apartados: el primero caracteriza la filosofía de Nietzsche como una hermenéutica fisiológica del poder; el segundo define la voluntad de poder a partir del carácter relacional y ficcional de las fuerzas, en este punto se plantea una lectura agonista de la filosofía política del filósofo de Röcken; en el tercero se retoma el modo de ser interpretativo de las fuerzas para mostrar que la voluntad de poder puede entenderse como voluntad de ficción; en el cuarto apartado se aborda la discusión sobre el sujeto y la consciencia de poder como su elemento constituyente; finalmente, después de volver sobre la constitución relacional y ficcional de la voluntad de poder, se esboza una subjetividad política como transformadora de sentidos y valoraciones.

El matiz hermenéutico ${ }^{1}$ de la filosofía de Nietzsche es reconocido por varios de sus intérpretes. Por ejemplo, Andrés Sánchez Pascual (1984) muestra que la interpretación la hereda de su pasado como filólogo, pero Nietzsche la extrapola a la filosofía. Por su parte, Conill (1997) señala que [130 ] la singularidad del tipo de pensamiento denominado como «hermenéutico» consiste en inscribir como método filosófico a la interpretación. En Nietzsche, este método prolonga y radicaliza el criticismo de la modernidad, «pero transformándolo en una hermenéutica de carácter genealógico, que estudia el origen del pensamiento y la fuente de los valores que ponen en juego la vida» (p. 96). Entonces, esta historia genética implica una "crítica de los valores» hecha desde la óptica de la vida entendida como voluntad de poder. Justamente, Nietzsche instaura «una concepción de la filosofía que incorpora la vida del sujeto humano en la reflexión y se atreve a plantear "el enigma de la vida y el mundo"»(Conill, 1997, p. 95). Esta filosofía ya

\footnotetext{
${ }^{1}$ No es objeto de este trabajo adentrase ampliamente en las discusiones existentes sobre el empleo del término hermenéutica en relación con Nietzsche. Por ello, al usar el concepto de hermenéutica se entiende que el pensamiento del filósofo alemán está atravesado por el problema de la interpretación, es decir, de la valoración y el sentido. Sobre el caso en cuestión, por ejemplo, la Sociedad Española de Estudios Sobre Friedrich Nietzsche (SEDEN) dedicó un congreso a discutir las relaciones entre la filosofía nietzscheana y la hermenéutica. En el prólogo de la revista producto del congreso se señala que el término no fue utilizado por Nietzsche en su obra publicada, sino en algunos fragmentos póstumos muy esporádicamente. Sin embargo, es claro que los problemas relacionados «con la experiencia del comprender o del interpretar» (Arenas, Giancristofaro y Stellino, 2009, p. 12) son abordados a lo largo de su vida.
} 
no daría prioridad a la ciencia, sino a la vida. En este camino aparece como tarea de El nacimiento de la tragedia: «ver la ciencia con la óptica del artista, y el arte, con la de la vida [...]» (Nietzsche, 2000a, p. 28).

En este marco de referencia, es posible resaltar que el problema central de Nietzsche es el valor de los valores —-transvaloración-. Para Sánchez (1984), la hermenéutica nietzscheana no consiste en examinar críticamente lo verdadero y lo falso, sino de sospechar, desenmascarar y mostrar el carácter ficcional de las verdades más preciadas. El trabajo de Nietzsche no consiste en ir mostrando que una verdad es mentira, pues, nos dice: «-iQué me importan a mí las refutaciones!—, sino cual conviene a un espíritu positivo, poniendo, en lugar de lo inverosímil, algo más verosímil, y, a veces, en lugar de un error, otro distinto» (p. 21). Este modo de proceder es denominado por Conill (1997) como hermenéutica genealógica y busca hacer una crítica de la racionalidad metafísica. Esta última forma de valorar dominante lleva a una negación de la vida y del sentido, es decir, al nihilismo: «la creencia en la absoluta falta de valor, es decir, en la falta de sentido» (Nietzsche, 2008, p. 221). Este amor a la nada — voluntad de nada- está encarnado para Nietzsche en el cristianismo y el espíritu moderno. Frente a esto su apuesta política consiste en fijar valoraciones y sentidos desde la óptica del cuerpo, la tierra y la vida.

Ahora bien, parte del proyecto de transvaloración de todos los valores implica el reconocimiento del carácter ficcional de toda experiencia, por tanto, de todas las verdades. En este marco de referencia es que la voluntad de poder puede entenderse como voluntad de ficción. Dicho concepto remite al hombre como un animal constituido por una conducta estética fundamental hacia la construcción de metáforas (Nietzsche, 2006). Esta producción constante de interpretaciones que permiten vivir es un proceso que Nietzsche extrapola a todo el mundo orgánico (Vaihinger, 2006, p. 69). En este sentido, sin embargo, parece que Paul Ricoeur (2006) se aleja de Nietzsche al decir que: «una vida no es más que un fenómeno biológico en tanto la vida no sea interpretada» (p. 17), pues para el filósofo de Röcken toda vida se desenvuelve interpretativamente.

Este marco hermenéutico de desenvolvimiento de la voluntad de poder está anclado en el cuerpo y, por tanto, en la fisiología. Así, la voluntad de creación se liga con la idea de que «el cuerpo es por naturaleza relación entre fuerzas dominantes y dominadas, que generan explosiones de perspectivas 
desde las cuales se constituye la vida creadora de máscaras» (Rocha, 2000. p. 172). Para Alfredo Rocha, a partir de esta definición de cuerpo es posible sustentar el perspectivismo desde la fisiología. El cuerpo es la raíz de la «voluntad de apariencia» - der Wille zum Schein-, de las producciones artísticas, por lo que es factible hablar de una fisiología del arte. Para Conill (1997), sin embargo, en el tercer periodo ${ }^{2}$ del pensamiento nietzscheano se da un giro desde la fisiología estética a la fisiología del poder.

Esta comprensión de la voluntad de poder y del cuerpo como constituido por relaciones entre las fuerzas es la base para hacer una lectura agonista —fisiológica - de la filosofía política de Nietzsche (Conill, 1997; Cifuentes, 2000). Este punto de partida fisiológico es usado por muchos para cimentar teorías totalitarias del superhombre desde el biologismo, empero, el filósofo alemán ve como decadentes las teorías que propugnan por un cerramiento del sentido: nada más alejado de su perspectivismo. De hecho, el punto de partida relacional de su teoría - una fuerza nunca es por sí misma, siempre en relación con otras- evita un individualismo absoluto; en oposición, sus planteamientos llevan a una defensa de la otredad (Lemm, 2013) y del carácter social de la existencia (Quejido, 2014) como punto de partida histórico para comprender los diferentes fenómenos como el hombre y la vida (Jara, 1998). En todo caso, dado que Nietzsche plantea alejarse del rebaño, puede preguntarse: ¿es posible, desde su teoría, plantear un proyecto colectivo que no ponga en riesgo la singularidad individual?

Esta composición de los cuerpos a partir de una pluralidad pulsional belicosa permite hablar de un agonismo interpretativo de base fisiológica, este es expresión del comportamiento ficcional de las fuerzas desde la vida orgánica elemental hasta cobrar consciencia en el hombre. Así, desde su uso inconsciente por el olvido hasta el uso consciente que le da el «hombre superior», el ser humano actúa como si fueran verdades las metáforas usadas para conocer el mundo; también, el individuo permanente y su unidad es, de modo similar, algo necesariamente imaginado (Vaihinger,

\footnotetext{
${ }^{2}$ El pensamiento de Nietzsche es dividido por sus intérpretes en tres etapas: la primera es delimitada por la metafísica estética edificada con base en el concepto de voluntad de Schopenhauer y el influjo de Wagner, la cual es representada por El nacimiento de la tragedia, aunque ya hay en esta obra una distancia con la interpretación moral del mundo de Schopenhauer. Esta primera etapa romántica termina con Humano demasiado humano, con la crítica a la metafísica ejercida desde la óptica de la ciencia; así, con esta máscara, en este periodo ilustrado intenta desmantelar también las valoraciones del arte y la religión. El periodo final o de elaboración definitiva es representado principalmente por Así habló Zaratustra, es la parte afirmativa de su filosofía.
} 
2006, p. 62), y a pesar de situarnos en medio del mundo de imágenes no deja de ser un error. De este modo, la consciencia de este carácter ficcional de la existencia y del poder de estas relaciones puede ser usada por las fuerzas activas para transfigurar las realidades existentes, consciencia que también debe ser entendida no en oposición al cuerpo, sino como expresión de los instintos. En suma, la consciencia debe entenderse desde la fisiología interpretativa como una construcción social (Quejido, 2014): «la conciencia es propiamente, una red de conexiones entre hombre y hombre» (Nietzsche, 1990, p. 218).

Con base en lo expuesto, la idea central de este trabajo es pensar una subjetividad política a partir del suelo fisiológico interpretativo que da la teoría política de Nietzsche, es decir, desde la comprensión de la voluntad de poder como voluntad de creación. Por ello se resalta lo que puede denominarse una política de la ficción, la cual parte precisamente del comportamiento ficcional de las fuerzas en el marco de las relaciones de poder. La formación de la subjetividad política con consciencia del carácter ficcional y relacional de toda experiencia apunta a la transvaloración de las estructuras de poder. Con esto se plantea la posibilidad de transfiguración de la subjetividad desde la defensa de la vida, de la pluralidad de perspectivas y del reconocimiento agonista de la alteridad. Así, la incorporación de la experiencia propia a la reflexión filosófica sirve de eje para hacer frente a las ópticas de cerramiento de sentido alimentadas por la voluntad de nada. De esta manera se resalta el carácter ficcional de la racionalidad corporal nietzscheana en el momento de pensar el sujeto político.

\section{La hermenéutica fisiológica del poder}

En esta parte se caracteriza la filosofía de Nietzsche como una hermenéutica fisiológica que dirige la mirada a la implantación de interpretaciones, valoraciones y sentidos dentro de las relaciones de poder entre las fuerzas. En este camino se explica la relación necesaria entre hermenéutica y voluntad de poder en el pensamiento del discípulo de Schopenhauer. Así, se tiene que la cuestión del valor de los valores es tratada también en La genealogía de la moral. Allí, Nietzsche postula que para realizar una crítica de los valores morales es importante buscar su «origen». Esto quiere decir que el ejercicio genealógico antecede al hermenéutico: «necesitamos una crítica de los valores morales, hay que poner alguna 
vez en entredicho el valor mismo de esos valores, y para esto se necesita tener conocimiento de las circunstancias de que aquellos surgieron [...]» (Nietzsche, 1984, p. 23). Los valores morales deben responder por su nocividad o afirmación de la vida, pues para el filósofo alemán su valor no ha sido sometido a crítica. Esto mismo ha sucedido con el valor de la verdad, por ello necesita ser puesto como problema. "La voluntad de verdad necesita una crítica - con esto definimos nuestra propia tarea- el valor de la verdad debe ser puesto en entredicho alguna vez, por vía experimental [...]» (p. 175).

Se hace evidente la importancia de comprender los conceptos de valor y sentido en la filosofía nietzscheana. Para ello debe remitirse al carácter interpretante del cuerpo, pues las valoraciones son expresiones del despliegue de las fuerzas que lo componen. Para Rocha (2000), Nietzsche establece una conexión entre el establecimiento de perspectivas y la producción de máscaras y apariencias. Estás ultimas están también vinculadas con el devenir de las fuerzas y la implantación de valoraciones (p. 161). Así, los valores se plasman en las cosas por medio de la interpretación resultante de la lucha de fuerzas: «ino es por necesidad el sentido precisamente sentido relacional y perspectiva? Todo sentido es voluntad de poder» (Nietzsche, 2008, p. 98). Por tanto, como señala Rocha (2000), «valorar es interpretar» (p. 163), e interpretar es asignar sentido en la dinámica de lucha de fuerzas, sentido determinado por la cualidad de la fuerza (Rocha, 2001, p. 71).

Ligados a los conceptos de valoración y sentido, la noción de fuerza es imprescindible para comprender el pensamiento nietzscheano, pues remite al tinte perspectivista y hermenéutico de su filosofía. Las fuerzas son voluntad de poder y su dinámica relacional y de lucha la despliegan interpretativamente. Por ello, si se dejara de lado dicho concepto y el de dominio para su comprensión, se cae en un punto de vista esteticista que no corresponde con la vida pública y política (Conill, 1997, p. 160). De este modo, la hermenéutica de la razón de Nietzsche encuentra que la actividad primordial de la vida es un «interpretar transvalorizador» (p. 159). Acorde con esto, la filosofía de Nietzsche se aleja de la contemplación y remite a una dinámica de la acción efectiva y transformadora: «valorar es crear». En los términos de Rocha (2001): «que la voluntad de poder interpreta, significa en primera instancia que su proceder es eminentemente valorativo, es decir, que el despliegue de la fuerza es creador de valoraciones» (p. 70). 
La vida para Nietzsche (2008) es el parámetro de medida de las valoraciones, pues es la vida misma la que valora. Es por esto que las valoraciones remiten siempre a una óptica de la vida: «la estimación de valor moral es una interpretación, un modo de interpretar. La interpretación misma es un síntoma de determinados estados fisiológicos [...]. ¿Quién interpreta? Nuestros afectos» (p. 134). Es decir, que toda valoración y producción de sentido remite a la configuración de diferentes centros de interpretación corporales. Por esto Rocha (2000) señala que «toda valoración es la expresión del desencadenamiento de una fuerza que se manifiesta como voluntad de producción de sentido mediada fisiológica, histórica y culturalmente» ( $p$. 161). Esto implica que las valoraciones remiten a una perspectiva implantada espacio-temporal y relacionalmente. Para Nietzsche, hasta este momento han gobernado los instintos decadentes encarnados en los valores cristianos morales absolutos, por tanto, se hace necesaria una nueva perspectiva que consiste en que la fisiología tome su lugar principal.

En concordancia, como parte del proyecto de la transvaloración de todos los valores, «la gran política hace que la fisiología se convierta en ama y señora de todas las otras cuestiones» (Nietzsche, 2008, p. 774). Así, el concepto de "gran política», hace referencia a la tarea de rescatar todo lo que el cientificismo moderno, la metafísica y el cristianismo rechazaron. Por ello, el cuerpo ${ }^{3}$ en el pensamiento nietzscheano cobra especial importancia, pues toma el lugar como centro de valoración e interpretación, como el hilo que guía su filosofía y como punto de partida de su crítica a la metafísica (Conill, 1997; Rocha, 2000). De esta manera, hay que remitirse al cuerpo para comprender la óptica de la vida, la voluntad de creación de máscaras, de metáforas y sustentar la defensa de la vida (Rocha, 2000, p. 164). De hecho, también implica repensar metódicamente a la filosofía y la vida misma: «si el que filosofa es el cuerpo, este es el terreno apto para experimentar, de modo que cualquier filosofía debe surgir como interpretación de lo fisiológico y del tipo de relaciones de fuerza que lo atraviesan y constituyen» (Cifuentes, 2000, p. 183).

\footnotetext{
${ }^{3}$ Rocha (2001) señala la diferencia que hay en el alemán entre der Körpe y der Leib. El primer término hace referencia a una aproximación biologicista y materialista del cuerpo; el segundo muestra un acercamiento a su carácter interpretativo. La corporalidad, «como escenario de creación de sentido» (p. 63). La corporalidad es el término más utilizado por Nietzsche.
} 
La hermenéutica genealógica de Nietzsche da pie a una comprensión de todos los fenómenos desde la animalidad y lo corpóreo del hombre: «se profundiza no biologicistamente en la biología humanas. Se "hermeneutiza" [...] el mundo de la fisiología» (Conill, 1997, p. 118). También se fisiologiza el mundo de la hermenéutica. En este sentido, en Nietzsche prevalece el cuerpo como punto nodal ante la preeminencia del hombre metafísico y moral. Así, es posible identificar los estados fisiológicos con las maneras de interpretar (Rocha, 2000). Esta lectura no biologicista del cuerpo, sino interpretativa, la aplica Nietzsche a los estados corporales denominados como salud y enfermedad: de un cuerpo biológicamente enfermo puede brotar una valoración afirmativa de la vida y de uno biológicamente sano puede emanar una interpretación decadente. Por tanto, estas ópticas de la vida que median las valoraciones no son determinadas únicamente desde la fisiología, sino también por los contextos sociales y culturales (Rocha, 2000). De esta manera, Nietzsche (1984) contrapone el pensar histórico al metafísico, pues el pecado original de los filósofos es no tener sentido histórico. En esta misma línea, resalta los fenómenos cotidianos como merecedores de atención filosófica (Nietzsche, 2003).

Por tanto, lejos de la comprensión del mundo metafísica, Nietzsche [136] resalta el devenir constante de todas las cosas. Por ello, dirigir la mirada a lo fisiológico permite comprender mejor la hermenéutica nietzscheana, sobre todo porque existe una asimilación entre cuerpo y vida, este último es un concepto central en su filosofía: «el cuerpo es inmanente a la vida. Su devenir, su historia, es la de los flujos y reflujos de las fuerzas primarias que lo han formado» (Cifuentes, 2000, p. 199). Estas relaciones de fuerza demarcan lo que es la vida: «este mundo es todo lo contrario de un mundo metafísico. Está presente en todo, porque no hay nada por fuera de estas relaciones» (p. 197). Es dentro del marco de lo relacional que se explican todos los fenómenos vitales: todas las valoraciones son expresiones de determinadas tonalidades afectivas:

La vida misma es para mí instinto de crecimiento, de duración, de acumulación de fuerzas, de poder: donde falta la voluntad de poder hay decadencia. Mi aseveración es que a todos los valores supremos de la humanidad les falta esa voluntad, que son valores de decadencia, valores nihilistas los que, con nombres más santos, ejercen el dominio (Nietzsche, 1987, p. 28). 
A partir de lo anterior, se entiende que Nietzsche, al realizar la genealogía de los valores, golpee su martillo contra el nihilismo, que para él está encarnado en el cristianismo y lo moderno. De este modo, para Nietzsche (1984) la interpretación que hace el ideal ascético de la vida está travesada por una voluntad de nada: «ese odio contra lo humano, más aún, contra lo animal, más aún, contra lo material, esa repugnancia ante los sentidos, ante la razón misma, el miedo a la felicidad y a la belleza, ese anhelo de apartarse de toda apariencia, cambio, devenir, muerte, deseo, anhelo mismo» (p. 185). En resumen, el nihilismo es amor a la nada, es querer la nada, pues: «el hombre prefiere querer la nada a no querer [...» (p. 186).

El ideal nihilista resulta de la expresión de una óptica fisiológica enferma. Para Nietzsche (1987), en las concepciones decadentes del cristianismo y del cientificismo se establece lo verdadero y lo falso. Frente a esto, el proyecto de la transvaloración hace «una viviente declaración de guerra y de victoria a todos los viejos conceptos de "verdadero" y "noverdadero"» (p. 36). Así, se hace evidente que el pensamiento nietzscheano tiene un tinte hermenéutico, fisiológico y político:

Pero ¿qué es la vida? Vida es voluntad de poder. La vida es jerarquía, estructura aristocrática, sensación de poder, en ella no hay solidaridad ni compasión; de sus procesos se encarga la fisiología (ihermenéutica!) de Nietzsche, que detecta los procesos de interpretación, valoración y jerarquización, que constituyen la voluntad de poder [...]. La gran política consiste en una hermenéutica fisiológica del poder (como fisiología política), que tiene la tarea de criar (formar) al hombre como dueño y soberano de la tierra (Conill, 1997, p. 191).

\section{La voluntad de poder: una política agonista del sentido}

La voluntad de poder puede abordarse desde una perspectiva hermenéutica que se vincula estrechamente con lo fisiológico (Rocha, 2001, p. 63). Por tanto, es entendida como producción de valoraciones y sentidos que tienen el cuerpo como «centro de gravedad». Para Rocha aquella puede ser comprendida como el despliegue creativo de interpretaciones que se apropian de la realidad. A partir de esta relación entre voluntad de poder y cuerpo es posible realizar una lectura agonista del pensamiento de Nietzsche en la que el «modelo de cuerpo [... es 
agonístico, en él se enfrentan las distintas relaciones de dominio entre las fuerzas que lo han formado. La voluntad de Poder, como vida, es el dinamismo de esas relaciones» (Cifuentes, 2000, p. 183).

Este enseñoreamiento de los «hechos» en el escenario corporal no es entendido por Nietzsche principalmente como «deseo de dominio». Así, lo relevante de «la distinción entre gobernantes y gobernados, no es la afirmación del poder sobre los otros sino, como se ha dicho, una afirmación de la diferencia como precondición para el conflicto y la lucha» (Lemm, 2013, p. 83). En este camino, Rocha (2001) diferencia entre poder -Machty dominio - Herrshaft- al subrayar que la voluntad de poder es voluntad de creación. De esta manera, señala que «mientras el poder creador de la voluntad genera y reconoce perspectivas y valoraciones que amplían las posibilidades de ser en el mundo, el deseo de dominio busca acallar las diferencias e implantar el sentido, haciéndolo unívoco y universal» (p. 66). Con base en esto puede afirmarse que, dado que la lucha es por la implantación de valoraciones y sentidos, «la historia entera de una "cosa", de un órgano, de un uso, puede ser así una ininterrumpida cadena indicativa de interpretaciones y reajustes siempre nuevos [...] la forma es fluida, pero el "sentido" lo es todavía más» (Nietzsche, 1984, p. 88). Es así como la hermenéutica nietzscheana se distancia de la forma metafísica de conocer que busca una esencia:

Si interpretar fuera sacar a la luz una significación enterrada en el origen, solo la metafísica podría interpretar el devenir de la humanidad. Pero si interpretar es apropiarse, violentamente o subrepticiamente, de un sistema de reglas que en sí mismo no tiene significación esencial, e imponerle una dirección, plegarlo a una nueva voluntad, hacerlo entrar en otro juego y someterlo a reglas secundarias, entonces el devenir de la humanidad consiste en una serie de interpretaciones (Foucault, 2008, p. 42).

Es factible afirmar que existe un agonismo interpretativo en la filosofía de Nietzsche: «se trata de una lucha por apropiarse de un territorio, por el reordenamiento o reinterpretación de las relaciones entre las fuerzas primordiales que funcionan como vida corporal» (Cifuentes, 2000, p. 193). Por ello, la historia de un órgano o institución remite a reapropiaciones de voluntades de poder mayores, pues «todo acontecer en el mundo orgánico es un subyugar, un enseñorearse, y que a su vez todo subyugar y enseñorearse 
es un reinterpretar, un reajustar [...]» (Nietzsche, 1984, p. 88). Es de este modo que todo fluye una y otra vez de acuerdo con «la esencia de la vida, su voluntad de poder» (p. 90).

Lo característico de la hermenéutica genealógica es reivindicar una racionalidad corpórea «que tiene la virtualidad de incorporar las interpretaciones, las valoraciones, el sufrimiento y la realidad, en una experiencia agonal de la vida» (Conill, 1997, p. 158). De esta manera, es una fisiología de la razón impura, que dirige la atención a lo que la metafísica desdeñó, la que descubre que «la fuerza emergente proviene de la voluntad de poder y consiste en un interpretar transvalorizador» (p. 159). Para Conill (1997) la transvaloración inscribe un momento de dominio que da lugar al «giro político» en el periodo final del pensamiento nietzscheano. Es así como ocurre un desplazamiento de la razón estética a la razón política que toma como fuerza hermenéutica a la capacidad de dominio — Herrschaft-.

El anterior giro se evidencia en Así habló Zaratustra y El anticristo en donde el punto de partida agonista se construye en una confrontación afirmativa contra el cristianismo, el espíritu moderno y todo lo que expida olor a decadencia (Conill, 1997). Sobre los evangelios, por ejemplo, Nietzsche dice: «cabalmente la antítesis de toda pugna, de todo sentirse a-sí-mismoen-la-lucha se ha vuelto aquí instinto: la incapacidad para poner resistencia se convierte aquí en una moral» (Nietzsche, 1987, p. 57). En consecuencia, el cristianismo representa "la exclusión instintiva de toda aversión, de toda enemistad, de todas las fronteras y distancias en el sentimiento» ( $p$. 58). De ahí que el pathos de la distancia reivindicado por Nietzsche desde una valoración aristocrática contraste con el modo de valorar cristiano. Justamente, el problema de la jerarquía atraviesa la obra del filósofo alemán y sobre ello en El anticristo señala cómo la política de igualdad de derechos del cristianismo «ha hecho una guerra a muerte a todo sentimiento de respeto y de distancia entre los hombres, es decir, al presupuesto de toda elevación, de todo crecimiento de la cultura» (Nietzsche, 1997, p. 76).

En este sentido, en la doctrina de Jesús no hay lugar para la antítesis ni la contradicción: «le falta absolutamente la libre imaginación del podervalorar-de-otro-modo y del poder-querer-de-otro-modo» (Nietzsche, 1987, p. 142). Por ello, el filósofo alemán contrapone los valores cristianos de la pasividad- a los aristocráticos — de la actividad-. Esto, dentro del problema de la jerarquía de los valores, Ileva a Nietzsche a denigrar del 
cristianismo y de la democracia por su idea de igualdad entre los hombres. De esta manera, se distancia del modelo político moderno, puesto que, para él, tanto el socialismo como la política burguesa se basa en la búsqueda de bienestar. En concordancia, Conill (1997) muestra que «Nietzsche acrecienta el dinamismo del poder. Su doctrina no está interesada en establecer de una vez para siempre un poder que garantice la paz y la autoconservación» (p. 187). Por tanto, la mirada agonista del pensamiento de Nietzsche deja ver la irreductibilidad del conflicto, tanto como la inscripción afirmativa del dolor a la vida.

En suma, la dinámica constante de la lucha de fuerzas por el poder implica que no se puede prescindir de esta como fuente de comprensión de los fenómenos sociales. En consecuencia, se requiere un tipo de pensamiento o de razón para leer las relaciones de poder: «la razón se ejercita ponderando (evaluando) las relaciones de fuerza» (Conill, 1997, p. 188). Esta forma de ver renovada es denominada por Nietzsche como perspectivismo: la capacidad de articular la experiencia corporal en la defensa de la multiplicidad de miradas. La vida, con todo y su carga de dolor se convierte en un experimento: «la vida es un medio de conocimiento» (Nietzsche, 1990, p. 186). En este sentido, existe un vínculo entre el pensamiento y la potencia creadora del cuerpo:

En el cuerpo son posibles muchos ensayos, muchas creaciones, eso puede ser la filosofía como una forma de vida. Probar con el cuerpo es permitir que él sea recorrido, experimentado por las fuerzas inmanentes de la vida. Esto es la filosofía como experimento y como riesgo, pero también como transfiguración, porque se puede afirmar a partir de lo que no parece afirmativo (Cifuentes, 2000, p. 183).

Esta posibilidad de transfiguración que se da desde la voluntad de ficción implica crear sentido rechazando el sinsentido. Ahora bien, la tarea no es permanecer en guerra abierta contra los estados de enfermedad, pues una de las maneras de enfrentarlas es pasar de largo: «la capacidad que se tiene de contener la fuerza» (Cifuentes, 2000, p. 190). Pese a esta alternativa, no puede negarse el marco relacional de toda actividad: «es interior $y$ exterior a lo viviente, porque es una fluctuación permanente, porque una fuerza es su relación con otras, es decir, de la fuerza no se sabe sino por sus relaciones, por sus aconteceres» (p. 190). De esta manera, no puede, de forma metafísica, establecerse un mundo para siempre. Precisamente, Antonio Cifuentes (2000) resalta que una de las consecuencias de esta lucha 
interminable por la reapropiación del sentido es que los regímenes de poder pueden transformarse, ya que están inmersos en las dinámicas temporales.

Por tanto, la «agonística somática» atraviesa las esferas de lo social, lo cultural y lo político. Con base en ella puede establecerse una forma de pensar que anclada en el cuerpo haga frente al pensamiento metafísico que «sólo quiere pensar pensamientos» (Cifuentes, 2000, p. 204). Para que este último no prospere se requiere al otro como polo a tierra. Un otro con el cual no necesariamente estar de acuerdo, sino un amigo otro, surgido de la oposición: «con ello se rescata el principio agonístico de la filosofía, su carácter de amistad, pero en la lucha, en el enfrentamiento con los iguales, en la fortaleza» (p. 205). De este modo, la agonística filosófica entendida como una forma otra de racionalidad estética está vinculada con una razón política. Así, puede abrirse el camino para pensar en una subjetividad que valore-actúe de otra manera, que haga frente a las lógicas nihilista de cerramiento de sentido.

\section{La voluntad de poder como voluntad de ficción}

Para Rocha (2001), entender la voluntad de poder como voluntad de creación ayuda a comprender mejor la apuesta de Nietzsche por una existencia abierta y afirmativa. Entonces, la «voluntad es en esencia producción de interpretaciones y perspectivas» (p. 65). Estas pueden ser entendidas como máscaras y apariencias que en su despliegue infinito permiten superar los dualismos entre cosa en sí-fenómeno, sujeto-objeto y verdad-mentira. A partir de allí se enfoca la mirada en este apartado, en la noción de voluntad de poder como voluntad de ficción, con el fin de allanar el terreno para postular la posibilidad de la formación de una subjetividad política dadora de sentidos y valoraciones a partir de la óptica de la vida. Una subjetividad que con base en su consciencia de poder tome las riendas de su transfiguración en resonancia con la alteridad.

Tanto en la obra publicada en vida como en la obra póstuma de Nietzsche existen diferentes maneras de abordar la voluntad de ficción o de ilusión (Vaihinger, 2006). En Sobre verdad y mentira en sentido extramoral, Nietzsche (2006) define al hombre como un animal fantástico poseedor de una conducta estética. Este creador de metáforas por medio del lenguaje inventa mundos asentados en el cuerpo que le permiten continuar viviendo a pesar del incesante devenir. Así, gracias al poder de la fantasía, el hombre como un ser artísticamente creador inventa el mundo estable del ser, los 
mismos objetos de la realidad y las formas para percibirlas: la causalidad, el número, el tiempo y el espacio. De este modo, el hombre, quien imprime valoraciones (Nietzsche, 1992), establece el sentido de las cosas por medio de la valoración: una y otra vez destruye y rehace el mundo por medio de la aniquilación de los antiguos valores.

Ahora bien, Hans Vaihinger (2006), en La voluntad de ilusión en Nietzsche, muestra las diferentes maneras de comprender la voluntad de ficción en los tres periodos de la obra nietzscheana. De este modo, señala que en los escritos de juventud aparecen la apariencia y la ilusión como necesarios no solo para el arte, sino también para la vida: el «hombre superior» es digno del uso consciente de la ilusión (p. 47). Por tanto, la vida, la cultura e incluso el conocimiento se sustentan en ficciones. De esta manera, al conocer cada uno usa sus metáforas favoritas, pues el intelecto trabaja con «símbolos conscientes», imágenes, figuras retoricas y todo el cúmulo de abstracciones.

En los escritos del periodo intermedio, el concepto de ficción tiene un tono menos ditirámbico y la palabra mentira es usada con menor frecuencia. Se encuentra que aún es inquietante la posibilidad de hacer un

[142] uso consciente del impulso artístico o mítico: "la comprensión del hecho de que las ideas, de cuya falsedad somos conscientes, son necesidades biológicas y teóricas se hace cada vez más clara» (Vaihinger, 2006, p. 54). Así, las creencias de todos los campos, como el científico, son solo «ficciones reguladoras», errores ópticos, es decir, leyes de una perspectiva que nos permiten vivir. La consciencia surge gracias a este mundo fantástico del error y es gracias a la creencia en lo permanente que podemos edificar el mundo del conocimiento: «mientras no ha surgido un mundo imaginario, en contradicción con el flujo absoluto, no ha sido posible erigir sobre tales cimientos una estructura del conocimiento [...] errar es la condición de vivir» (p. 56).

En este sentido, el intelecto es presentado como medio y maestro del engaño: sustancia, identidad y permanencia los encontramos en el mundo luego de que los pusimos ahí: «sólo conocemos a priori de las cosas lo que nosotros mismos ponemos en ellas» (Kant, 2006, p. 21). Ahora bien, para Nietzsche «el pensamiento depende del lenguaje, y el lenguaje ya está lleno de presupuestos falsos [...] estos constituyentes míticos y ficticios del lenguaje deben ser empleados con la consciencia de su falsedad» 
(Vaihinger, 2006, p. 57). De este modo, simplificamos las cosas y tomamos la unidad por el todo; actuamos como si el mundo fuera simple y unitario. Precisamente, la idea kantiana de que nos asombramos de encontrar las cosas que hemos puesto en la naturaleza produjo una impresión fuerte en Nietzsche: «es justamente esta fuerza de la mente "creadora", "activa", su actividad "inventiva", poética y falsificadora, lo que Nietzsche [... subraya repetidamente» (p. 60).

De hecho, creación y transformación desempeñan un papel importante en el momento en que Nietzsche nombra a Dioniso como el dios filósofo. «La filosofía de Dionisos se introduce, por lo tanto, no sólo como una solución a problemas no resueltos, sino también como un nuevo "modo de pensar"» (De Santiago, p. 2000, p. 137). Esta nueva forma de pensamiento reconoce el placer que tiene crear y transformar tanto al hombre como a la existencia.

El mundo del ser es un artificio del intelecto ante la imposibilidad de conocer el flujo constante del devenir; sin embargo, «la única existencia de la que tenemos alguna garantía es mudable, no idéntica en sí misma, y posee relaciones» (Nietzsche, citado en Vaihinger, 2006, p. 61). En concordancia, también el mundo moral es una ficción que para Nietzsche resulta útil y con ella hacemos "como si mostráramos el camino a la naturaleza" en nuestros actos, mientras en verdad hemos sido conducidos por ella [...]. Nuestra libertad, nuestra autonomía, es una "interpretación", es decir, algo "leído en"» (Nietzsche, citado en Vaihinger, 2006, p. 63). Esto muestra el vínculo entre interpretación y ficción, pues la voluntad de poder, dado su carácter hermenéutico, puede entenderse como voluntad de ficción.

Ahora bien, para Vaihinger (2006) el tercer periodo del pensamiento nietzscheano está atravesado por el problema del «valor de la verdad». Así, Nietzsche se posiciona no solo más allá del bien y del mal, sino también de la verdad y la falsedad: "la perspectiva es la condición básica de toda vida» (Nietzsche, citado en Vaihinger, 2006, p. 68). En este sentido, muestra cómo algunas ficciones se han posicionado como la verdad en sí. Estas ficciones in malo sensu, como las metafísicas, cristianas y nihilistas, se arrogan el estatus de realidades. Es de esta manera «cómo el mundo verdadero acabó convirtiéndose en una fábula» (Nietzsche, 1998), y con ello el sujeto que lo representa se hace uno solo con él. De acuerdo con este realce de la capacidad de metaforizar del hombre, para Vaihinger (2006) existe en Nietzsche una metafísica del como sí: 
Existe únicamente un ver perspectivista, únicamente un "conocer» perspectivista; y cuanto mayor sea el número de afectos a los que les permitamos decir su palabra sobre una cosa, cuanto mayor sea el número de ojos, de ojos distintos que sepamos emplear para ver una misma cosa, tanto más completo será nuestro concepto de ella, tanto más completa será nuestra objetividad (Nietzsche, 1984, p. 139).

\section{La constitución relacional de la subjetividad política: consciencia de poder}

La cuestión de la subjetividad en Nietzsche debe remitirse indudablemente a algunos elementos y conceptos centrales de su filosofía, entre ellos, tener en cuenta la crítica general de la metafísica, su forma de pensar y de entender las cosas como emanadas de un principio universal y eterno. Detrás del modo de pensar metafísico se encuentra la voluntad de nada, el nihilismo, la negación del sentido y de la vida. Por tanto, una comprensión nietzscheana del sujeto se enmarca en la voluntad de poder que está íntimamente relacionada con la vida: «la vida misma es voluntad de poder» (Nietzsche, 2000b, p. 36). Si se atiende a la constitución relacional de la voluntad de poder, entendida como lucha de fuerzas, pueden comprenderse tanto los fenómenos orgánicos como sociales e incluso al sujeto en el marco de estas relaciones. De igual forma, la definición de la voluntad de poder como cuerpo implica que el sujeto debe pensarse en esa sintonía que es acorde con su proceder interpretativo y, por tanto, ficcional: «nuestro cuerpo, en efecto, no es más que una estructura social de muchas almas. L'effect c'est moi [el efecto soy yo]»(p. 43).

De esta manera, se encuentra un nuevo modo de abordar el sujeto y sus formas de valorar, pues este se encuentra dentro de las verdades más sagradas que, para Nietzsche, deben ser desmontadas. En el marco de la filosofía nietzscheana, el sujeto es una de las ficciones necesarias para continuar viviendo frente al flujo constante del devenir. Es posible pensarlo como un campo de fuerzas en constante lucha que no le permiten fijar una identidad. Por ello es posible enfocar la atención en el carácter relacional -social- del sujeto. En este marco de ideas, se explora en este apartado el término de consciencia de poder utilizado por Nietzsche para pensarlo como elemento de la formación de la subjetividad política.

A partir del campo de lo relacional es posible comprender todos los fenómenos, incluidas la subjetividad y la consciencia. Lo vivo, por 
ejemplo, es factible gracias a la voluntad de poder y las relaciones de fuerza que «permiten que lo humano individual surja también como cuerpo o, más bien, como sí-mismo [...] nuestra fisiología es inmanente a la vida» (Cifuentes, 2000, p. 199). Por consiguiente, la hermenéutica nietzscheana tiene su punto de partida en el cuerpo y no en la consciencia o en el lenguaje: «el núcleo del ser humano ha dejado de ser la consciencia, como venía siendo habitual en las corrientes preponderantes de la filosofía moderna, y se traslada al organismo» (Conill, 1997, p. 116). Poner lo fisiológico como punto de partida constituye un marco de pensamiento para comprender los retos que tiene la subjetividad en el mundo actual. De igual manera, la crítica de Nietzsche al nihilismo toma fuerza para enfrentar un mundo que convierte en mercancía a todas las cosas, incluidos los recursos naturales y el hombre, incluso el sentido.

Ahora bien, para acercarse a la noción de subjetividad en Nietzsche es necesario remitirse a la problemática de la verdad y del ente (Vermal y Llinares, 2008). Como se afirmó antes, la verdad está sustentada en la ficción, por lo que no importa tanto la verdad por sí misma, sino la actividad interpretativa que la produce. Así, la vida se convierte en el parámetro de medida de los juicios y verdades, con lo que se demuestra que Nietzsche (2000b) está lejos del relativismo absoluto: «la cuestión está en saber hasta qué punto ese juicio favorece la vida, conserva la vida» ( $p$. 25). En Nietzsche ocurre la radicalización del proyecto moderno, en tanto la actividad de interpretar que origina la verdad tiene sus bases en el sujeto (Vernal y Llinares, 2008); sin embargo, señalar que todo es subjetivo es una interpretación más (Nietzsche, 2008, p. 222).

El sujeto es producido por la acción interpretativa y, dado que esta depende de la voluntad de poder, "es el poder el que es productivo, productor del sujeto mismo» (Conill, 1997, p. 183). En este sentido, las creaciones de la voluntad deben entenderse como expresiones de fuerzas activas o reactivas. Las primeras actúan desde sí mismas, las segundas actúan en respuesta al exterior. La acción de las fuerzas remite a ellas mismas y no a un elemento originario: "tal sustrato no existe; no hay ningún "ser" detrás del hacer, del actuar, del devenir; "el agente" ha sido ficticiamente añadido al hacer, el hacer es todo» (Nietzsche, 1984, p. 52). En suma, no hay un sujeto detrás de la acción que se despliegue como debilidad o fortaleza. 
Entonces, es el cuerpo concebido como una pluralidad de fuerzas el que sirve de sustento a Nietzsche para ir en contra de la forma convencional de entender al sujeto. Es decir, el yo no es entendido como una cosa prefijada e idéntica a sí misma, sino que el yo expresa la multiplicidad instintiva y conflictiva del cuerpo: "cuando decimos "yo" nos referimos a una concentración determinada de fuerzas, de energía, a un campo sometido a un equilibrio inestable» (Ávila, 1999, p. 195). Frente a este mundo cambiante, el hombre crea ficciones que le permitan seguir viviendo. Estas son posibles dado «que el hombre es el único animal que tiene consciencia de sí mismo y capacidad de autorreflexión. Pero esta consciencia de sí [...] es también el origen de ideas delirantes, de ficciones [...] de la ficción del yo» (p. 194). Entonces, el sujeto es resultado de la pluralidad y entender el proceso de manera inversa es una manera de negar la vida. Pensar en un sujeto como una unidad cohesionada que produzca la pluralidad es un ejemplo de los peligros que se corre de que las ficciones no sean tomadas como reguladoras, sino como algo real (p. 77).

Nietzsche critica la mirada dualista para hacer frente a las ficciones que niegan la vida, entre ellas las de la metafísica y las derivadas de la separación entre el ser y la apariencia. Al posicionar el cuerpo como centro de interpretación se replantea el lugar de la consciencia, al entenderla no en oposición a este, sino en continuidad ontológica y axiológica. De igual forma, los dualismos cuerpo-alma, cuerpo-mente, derivados de la separación entre lo sensible y lo inteligible, son puestos en duda (Quejido, 2014). Para Nietzsche, el pensamiento metafísico está cimentado sobre la falsa superstición del alma, "la cual, en cuanto superstición del sujeto y superstición del yo, aún no ha dejado de causar daño» (Nietzsche, citado en Quejido, 2014, p. 48). Por tanto, colocar al espíritu puro como eje del conocimiento es una forma equivocada de buscar la verdad y que no concuerda con el perspectivismo vital. Nietzsche revisa las dualidades impuestas por la metafísica y así, por ejemplo, mediante la revisión de la noción de consciencia, introduce "las esferas de lo lingüístico, de la comunicación y de las relaciones sociales» (Quejido, 2014, p. 49).

Ahora bien, es necesario recordar el piso fisiológico de la filosofía de Nietzsche para comprender también la noción de consciencia: «tenemos que contar entre las actividades instintivas la parte más grande del pensar consiente [...] tampoco es la consciencia antitética de lo instintivo» (Nietzsche, 2000 b, p. 24). Por ello existe un realce de los instintos inconscientes sobre 
la inteligencia premeditada. Acorde con esto, parte del espíritu aristocrático está ligado a la capacidad de olvido: «no poder tomar mucho tiempo en serio los propios contratiempos, las propias fechorías, tal es el signo propio de naturalezas fuertes y plenas, en las cuales hay una sobreabundancia de fuerza plástica, remodeladora, regeneradora, fuerza que también hace olvidar» (Nietzsche, 1984, p. 45). Frente al animal del instante fue necesario, sin embargo, crear una memoria, hacerlo regular para que pudiera hacer promesas. Nietzsche Ilama «eticidad de la costumbre» al colosal trabajo del hombre sobre sí mismo y por medio del cual se formó «hasta cierto grado, necesario, uniforme, igual entre iguales, ajustado a la regla, y, en consecuencia, calculable» (p. 67). Al terminar este proceso se encuentra el individuo soberano que está al otro lado de la eticidad, aquel al que le es lícito hacerse promesas a sí mismo y mantenerlas ante las adversidades. Él mismo es su medida de valor. En este sentido, por ejemplo, puede existir una sociedad que tenga una «consciencia de poder» que le permitiera «dejar impunes a quienes le han dañado» (p. 83).

Para el individuo soberano saberse poderoso y responsable «se ha convertido en instinto, en instinto dominante: - ¿Cómo llamará a este instinto dominante, suponiendo que necesite una palabra para él? Pero, no hay ninguna duda: este hombre soberano lo llama su conciencia [...]» (Nietzsche, 1984, p. 68). Ahora bien, al lado de la noción de consciencia activa, Nietzsche caracteriza la mala consciencia a partir de aquellos que vuelcan sus instintos sobre sí mismos: «todos los instintos que no se desahogan hacia fuera se vuelven hacia dentro .... ese es el origen de la "mala consciencia"» (p. 96). Esto permite identificar, en todo caso, la posibilidad que tiene el hombre del resentimiento de hacer un cambio en la dirección de los afectos y culparse de su sufrimiento: «el sacerdote es el que modifica la dirección del resentimiento» (p. 147). Precisamente Judith Butler (2001) señala que «Nietzsche atribuye poder creativo o formativo a la consciencia, por lo cual el acto de volverse sobre sí mismo no es solo la condición de posibilidad del sujeto, sino la condición de posibilidad de la ficción, la invención y la transfiguración» (p. 79).

Del redireccionamiento y transfiguración del espíritu nos habla Zaratustra, de cómo el espíritu se transforma de camello en león y finalmente en niño. El camello obedece sin ver y suplica por ser cargado: «Hay muchas cosas pesadas para el espíritu, para el espíritu fuerte, paciente, en él habita la veneración: su fortaleza demanda cosas pesadas, e incluso las más pesadas 
de todas» (Nietzsche, 1992, p. 49). En contra de los valores imperantes se levanta el león para cambiar el «tú debes» por el "yo quiero»: «en lo más solitario del desierto tiene lugar la segunda transformación: el león se transforma aquí en espíritu, quiere conquistar su libertad como se conquista una presa, y ser señor en su propio desierto» (p. 50). Sin embargo, el león rompe las cadenas de obediencia y renuncia a los valores milenarios, más no puede crear nuevos valores. Se necesita que el león se transforme en niño, en un niño que juega en el mar creando nuevos mundos: «inocencia es el niño, y olvido, un nuevo comienzo, un juego, una rueda que se mueve por sí misma, un primer movimiento, un santo decir sí» (p. 51). «Todo lo que es profundo ama la máscara» (Nietzsche, 2000b, p. 69).

\section{Conclusiones: la transfiguración de la subjetividad política a partir de la voluntad de ficción}

La crítica realizada por Nietzsche a la metafísica pone en entredicho la idea de un sujeto que fundamenta el mundo y que se postule como una entidad racional transparente y autosuficiente. En todo caso, lejos de desterrar al sujeto, Nietzsche plantea que debe reconocerse que es una ficción necesaria. En este sentido, el filósofo de Röcken posibilita construir

[148] nuevas formas de subjetividad y subjetivación a partir del reconocimiento del carácter interpretativo y, por tanto, ficcional de toda experiencia. El sujeto debe entenderse como un organismo fisiológicamente constituido dentro del campo de la lucha entre las fuerzas, acorde con la comprensión de que la voluntad de poder, en tanto cuerpo, se desenvuelve interpretativamente. Esto tiene fuertes implicaciones en el campo de la formación política, al brindarnos un marco alternativo a los registros tradicionales de racionalidad. Poner en el centro del pensamiento y de la acción política a la ficcionalidad del cuerpo hace frente a la forma tradicional de entender la verdad. Desde aquí pueden construirse nuevas maneras y categorías para leer el mundo y la experiencia.

Así, a partir del proyecto de transvaloración de todos los valores, entendido como una empresa política, puede pensarse en la transfiguración de la propia subjetividad y la creación de nuevos valores desde la óptica del cuerpo, la tierra y la vida. Desde la noción de voluntad de poder de Friedrich Nietzsche es posible pensar la formación de una subjetividad política con consciencia de poder del carácter ficcional y relacional de la experiencia, en este sentido se hace frente a la voluntad de nada; además, se 
abre el marco de reconocimiento de la alteridad dentro de la irreductibilidad del conflicto. Esto hace que cobre fuerza el pensamiento de Nietzsche en la actualidad para pensar y efectuar formas de subvertir las construcciones convencionales de la realidad, lo que puede ampliarse a diferentes esferas práctico-teóricas como la educativa para comprender tanto las dinámicas de la vida escolar como las de formación de la subjetividad. De este modo, la dimensión estético-política del discípulo de Dioniso permite pensar la cotidianidad escolar desde una óptica política que involucre la formación afirmativa de la subjetividad. Esto puede impactar las categorías tradicionales de construir y entender la organización política.

\section{Referencias bibliográficas}

1. Arenas, Francisco; Giancristofaro, Lucas y Stellino, Paolo. (2009). Prólogo. Estudios Nietzsche. 9, pp. 9-13.

2. Ávila, Remedios. (1999). Identidad y tragedia. Nietzsche y la fragmentación del sujeto. Barcelona: Crítica.

3. Butler, Judith. (2001). Mecanismos psíquicos de poder. Teorías sobre la sujeción. Madrid: Cátedra.

4. Cifuentes, Antonio. (2000). Cuerpo y filosofía en el Zaratustra de Nietzsche. Universitas Philosophica, 34-35, pp. 179-207.

5. Conill, Jesús. (1997). El poder de la mentira. Nietzsche y la política de la transvaloración. Madrid: Tecnos.

6. De Santiago, Luis. (2000). La apolinización de Dionisos: la estética del último Nietzsche. Universitas Philosophica, 34-35, pp. 133-158.

7. Foucault, Michel. (2008). Nietzsche, la genealogía, la historia. Madrid: Pretextos.

8. Jara, José. (1998). Nietzsche un pensador póstumo. El cuerpo como centro de gravedad. Barcelona: Anthropos.

9. Kant, Inmanuel. (2006). Crítica de la razón pura. México, D. F.: Taurus.

10. Quejido, Óscar. (2014). ¿Qué hay más allá de la conciencia? La reelaboración nietzscheana de las relaciones cuerpo-mente en términos de poder. Hybris, 5 (2), pp. 47-60.

11. Ricoeur, Paul. (2006). La vida un relato en busca de narrador. Agora, 25 (1), pp. 9-22.

12. Rocha, Alfredo. (2000). El cuerpo como centro de interpretación. Universitas Philosophica, 34-35, pp. 159-178.

13.Rocha, Alfredo. (2001). La voluntad de poder en perspectiva fisiológica: la voluntad de creación como expresión de la salud. Universitas Philosophica, 37, pp. 61-94. 
14.Lemm, Vanesa. (2013). Nietzsche y el pensamiento político contemporáneo. Santiago: FCE.

15. Nietzsche, Friedrich. (1984). La genealogía de la moral. Madrid: Alianza.

16. Nietzsche, Friedrich. (1987). El Anticristo. Bogotá, D. C.: Planeta.

17. Nietzsche, Friedrich. (1990). La ciencia jovial, Caracas: Monte Ávila.

18. Nietzsche, Friedrich. (1992). Así habló Zaratustra. Madrid: Alianza.

19. Nietzsche, Friedrich. (1998). Crepúsculo de los ídolos. Madrid: Alianza.

20. Nietzsche, Friedrich. (2000a). El nacimiento de la tragedia. Madrid: Alianza.

21. Nietzsche, Friedrich. (2000b). Más allá del bien y del mal. Madrid: Alianza.

22. Nietzsche, Friedrich. (2003). Ecce Homo. Madrid: Alianza.

23. Nietzsche, Friedrich. (2006). Sobre verdad y mentira en sentido extramoral. Madrid: Tecnos.

24. Nietzsche, Friedrich. (2008). Fragmentos póstumos (1885-1889) Volumen IV. Madrid: Tecnos.

25. Sánchez Pascual, Andrés. (1984) Introducción. En: Nietzsche, Friedrich. La genealogía de la moral. Madrid: Alianza.

26. Vaihinger, Hans. (2006). La voluntad de ilusión en Nietzsche. Madrid: Tecnos.

27. Vermal, Juan Luis y Llinares, Juan B. (2008). Introducción. En: Nietzsche, Friedrich. Fragmentos póstumos (1885-1889) Volumen Iv. Madrid: Tecnos. 